\title{
REFLEXÕES QUANTO A EFETIVIDADE DAS REGIÕES GEOGRÁFICAS IMEDIATAS DA MATA SUL PERNAMBUCANA
}

\author{
Gustavo Souza Barbosa ${ }^{1}$
}

\section{Resumo}

O texto analisa a efetividade das Regiões Geográficas Imediatas, recortes regionais mais recentes delimitados pelo Instituto Brasileiro de Geografia e Estatística (IBGE), localizadas na Mata Sul pernambucana. Como objetivos específicos busca-se apresentar alguns dos conceitos de Região e a importância da análise regional para a ciência geográfica; registrar os recortes regionais delimitados pelo IBGE ao longo do tempo e sua metodologia; descrever a Mata Sul e suas diferentes regionalizações; identificar as relações entre os centros urbanos regionais; e inventariar a presença de órgãos governamentais, estabelecimentos de saúde e de educação básica e empresas nas novas regiões. A partir da análise documental em estudos do próprio IBGE e coleta de dados em sites governamentais conclui-se que algumas das Regiões Geográficas Imediatas da Mata Sul pernambucana não configuram-se efetivamente como tais.

Palavras-chaves: Região. IBGE. Mata Sul Pernambucana. Regiões Geográficas Imediatas.

\section{REFLECTIONS ON THE EFFECTIVENESS OF THE IMMEDIATE GEOGRAPHIC REGIONS IN THE MATA SUL PERNAMBUCANA, BRAZIL}

\begin{abstract}
The text analyzes the effectiveness of the Immediate Geographic Regions, the most recent regional clippings delimited by the Brazilian Institute of Geography and Statistics (IBGE), located in Mata Sul Pernambucana, Brazil. The specific objectives are to present some of the concepts of Region and the importance of regional analysis for geographic science. Record the regional clippings delimited by IBGE over time and its methodology. Describe Mata Sul and its different regionalization. Identify relationships between regional urban centers. Inventory the presence of government agencies, health and basic education establishments, and businesses in the new regions. From the documentary analysis of IBGE's own studies and data collection on governmental websites, it concludes that some of the Immediate Geographic Regions of Mata Sul Pernambucana are not effectively configured as such.
\end{abstract}

Key words: Region. IBGE. Mata Sul Pernambucana. Immediate Geographic Regions

\footnotetext{
${ }^{1}$ Mestrado em Geografia pela Universidade Federal de Pernambuco (2015); Professor de Ensino Básico, Técnico e Tecnológico do Instituto Federal de Educação, Ciência e Tecnologia de Pernambuco - Campus Recife E-mail: gustavosouza@ recife.ifpe.edu.br 


\section{RÉFLEXIONS SUR L'EFFICACITÉ DES RÉGIONS GÉOGRAPHIQUES IMMÉDIATES DE LA MATA SUL PERNAMBUCANA, BRÉSIL}

\section{Résumé}

Le texte analyse l'efficacité des Régions Géographiques Immédiates, les dernières coupures régionales délimitées par l'Institut Brésilien de Géographie et de Statistique (IBGE), situé à Mata Sul Pernambucana. Les objectifs spécifiques sont de présenter certains des concepts de région et l'importance de l'analyse régionale pour la Géographie; enregistrer les coupures de presse régionales délimitées par IBGE dans le temps et sa méthodologie; décrire Mata Sul et ses différentes régionalisations; identifier les relations entre les centres urbains régionaux; et inventorier la présence d'agences gouvernementales, d'établissements de santé et d'éducation de base et d'entreprises dans les nouvelles régions. L'analyse documentaire des études de l'IBGE et la collecte de données sur des sites Web gouvernementaux permettent de conclure que certaines des nouvelles Régions ne sont pas configurées efficacement en tant que telles.

Mots-clés: Région. IBGE. Mata Sul Pernambucana. Régions Géographiques Immédiates.

\section{INTRODUÇÃO}

O espaço geográfico é dinâmico. A atuação de diversos processos de ordem política, ambiental, cultural e socioeconômica promove tanto a homogeneização quanto a diferenciação espacial. À medida que determinados processos ocorrem de forma similar em certa escala torna uma porção do espaço mais semelhante entre si e, concomitantemente, a diferenciada das demais. É a dinamicidade dos processos e seu reflexo no espaço que permite a delimitação de recortes que possuam algum grau de semelhança, ou seja, é ela que origina as regiões, assim como demanda, seja como fim, seja como meio, a análise regional.

A partir da reflexão quanto às transformações e permanências no espaço geográfico nacional o IBGE tem promovido sucessivas propostas de delimitação regional para o Brasil com base nos mais variados critérios, o que, apesar de configura-se como um desafio, dada a extensão e heterogeneidade territorial do país, permite uma maior análise quanto às novas espacialidades formadas e sua efetiva validade como recorte único, singular.

Com base nas diversas definições do termo região e tomando-se a análise regional como importante elemento de contribuição para a Geografia o presente texto possui como objetivo geral analisar a real existência dos mais recentes espaços regionais identificados pelo IBGE (2017), intitulados Regiões Geográficas Imediatas, localizados na Zona da Mata Sul 
Pernambucana. Como objetivos específicos visa-se apresentar alguns dos conceitos de Região e a importância da análise regional para a ciência geográfica; registrar a variada regionalização proposta pelo IBGE e sua metodologia de delimitação; descrever a Zona da Mata Sul do estado de Pernambuco e seus diversos limites; identificar as relações entre os centros urbanos regionais; e inventariar a existência de órgãos governamentais, estabelecimentos de saúde e educação e empresas nas novas regiões instituídas. Parte-se da hipótese que nem todas as Regiões Geográficas Imediatas localizadas na Mata Sul pernambucana efetivamente podem ser consideradas como tais

Como metodologia adotou-se a análise documental sobretudo a partir de estudos do próprio IBGE quanto à definição de recortes regionais para o Brasil e da rede urbana nacional. A coleta de informações em sites governamentais foi utilizada como forma de obtenção de dados quanto à presença ou não de determinados órgãos nas Regiões em estudo.

O presente texto encontra-se organizado em cinco seções. A primeira traz uma breve reflexão quanto ao conceito de Região, sua importância e significado para a Geografia, e as contribuições da análise regional para os estudos geográficos. O item seguinte apresenta uma retrospectiva quanto às divisões regionais propostas pelo IBGE desde 1940 até 2017, na qual são destacadas as nomenclaturas adotadas e a metodologia de definição de cada recorte. $\mathrm{Na}$ terceira seção são abordados aspectos relacionados à caracterização da Zona da Mata Sul de Pernambuco e os diferentes recortes propostos pelo IBGE para a região. A quarta seção apresenta a relação dos centros urbanos locais entre si e com cidades exteriores aos seus recortes. No último item, referente à presença de órgãos governamentais, estabelecimentos de saúde e educação básica e atuação de empresas, é realizado um levantamento quanto à existência de tais elementos em cada um dos novos recortes regionais propostos.

Nas considerações finais, como forma de contribuição quanto à analise regional e reflexão sobre a delimitação de regiões, sobretudo a partir de critérios técnicos e administrativos, discorre-se quanto à efetividade das Regiões Geográficas Imediatas da Zona da Mata Sul de Pernambuco como recortes capazes de preencher os requisitos estabelecidos pelo próprio órgão que os instituiu, assim como são propostas novas possibilidades de regionalização para o espaço geográfico em debate.

\section{REGIÃO E ANÁLISE REGIONAL}


A temática regional é antiga na ciência geográfica, assim como o próprio termo região, desde cedo presente tanto nas análises de importantes autores, como o próprio La Blache, quanto no "linguajar do homem comum" (CORRÊA, 1990, p.22). Por mais que a questão regional tenha passado por diferentes momentos, da depreciação à valorização e vice-versa, a região não deixou de fazer parte do cotidiano do geógrafo e do não geógrafo, tornando-se, conforme Santos (2008, p. 137), a busca por uma divisão regional mais adequada "uma das maiores preocupações do geógrafo e do planejador". Neste sentido, ao menos para a Geografia, torna-se necessário, primeiramente, uma maior reflexão quanto ao termo região.

Segundo Lencioni (2009, p. 23), "a noção de região, da forma mais genérica possível, contém a ideia de parte de um todo", por sua vez, Dollfus $(1978$, p. 99) reitera que "o espaço regional não é uma porção qualquer da superfície terrestre [...]. É uma porção organizada de acordo com um sistema e que se insere num conjunto mais vasto".

Corrêa (1990, p. 22, grifo do autor) ressalta que tanto para o homem comum quanto para a Geografia o termo região "está ligado à noção fundamental de diferenciação de área, quer dizer à aceitação da ideia de que a superfície da Terra é constituída por áreas diferentes entre si”. Para Santos (2012), são os recursos (população, força de trabalho, capital, excedentes, etc.) que, distribuídos de diferentes formas e combinados localmente a cada momento histórico, são responsáveis por tal diferenciação dentro do espaço total, conferindo a cada lugar ou região "sua especificidade e definição particular" (SANTOS, 2012, p. 165)

Conforme Kayser (1975 apud DOLLFUS, 1978, p. 105), a região é

uma fração da superfície terrestre inscrita em um quadro natural que tanto pode ser homogêneo como diversificado, moldado por comunidades interligadas por relações de complementaridade e organizadas em torno de um ou de vários centros mas todas dependentes de um conjunto mais vasto.

As variadas definições de região, tais como, "parte de um todo" (LENCIONI, 2009), “porção organizada de um sistema" (DOLLFUS, 1978), “área diferenciada" (CORRÊA, 1990) trazem imprecisão. O que seria o todo? A natureza? A sociedade? O planeta? A região é a porção organizada de que sistema? Natural? Social? Econômico? Seria a região uma área diferenciada em relação aos seus aspectos físicos? Humanos? Socioeconômicos? É a imprecisão do termo, reconhecida pelo próprio Dollfus (1978), que transparece por meio da quantidade e variedade de adjetivos que o acompanham, originando-se assim não só a região, 
mas uma região "natural”, "histórica” (DOLLFUS, 1978), "homogênea” (IBGE, 1970), "intermediária", "imediata" (IBGE, 2017) dentre tantas outras.

As próximas mas imprecisas definições do termo região e a série de adjetivações que possui abrem um leque para reflexões quanto a sua natureza, contribuindo para a análise regional, a qual, segundo Dolffus (1978, p. 107), possui como objeto

\begin{abstract}
a área de extensão de um fenômeno susceptível de conferir individualidade a uma parte do espaço; implica o estudo do mecanismo dos processos que se combinam em sistemas que por sua vez explicam a criação, o crescimento e o deperecimento de uma região. Mas implica também, como toda pesquisa geográfica, o estabelecimento de comparações. Os estudos regionais não consistem apenas em monografias [...] Esses estudos exigem igualmente que cada fenômeno seja situado no interior de uma escala e que se observem as relações estabelecidas nos diferentes níveis, desde as combinações locais até os grandes conjuntos espaciais.
\end{abstract}

A análise regional, portanto, consiste na identificação do(s) processo(s) responsável(is) pela individualidade do recorte e na sua escala de atuação. Em outras palavras, determina-se o "tipo" da região, seu "adjetivo" (natural, econômica, urbana, etc.) e seus limites territoriais, todos, porém, mutáveis ao longo do tempo, no espaço e segundo decisões do agente de delimitação regional. No presente artigo, por exemplo, considerou-se a escala de atuação de determinada instituição governamental bem como as relações por ela elencadas como relevantes na proposta de regionalização que apresenta, relações que nem sempre restringemse ao espaço regional proposto, corroborando para o questionamento das próprias regiões estabelecidas e para o constante retorno à análise regional.

Seja ponto de partida ou de chegada, a análise regional faz-se presente nos estudos geográficos como uma forma de afirmação ou negação quanto aos recortes regionais propostos e identificação das limitações impostas pelo(s) elemento(s) considerado(s). É neste sentido que o presente texto busca contribuir para a análise regional, demonstrando que a realidade concreta esmiuçada em alguns de seus detalhes se afasta do teórico, no caso, do político-administrativo, quanto à definição de novas regiões, ou seja, busca-se apresentar que qualquer recorte regional tem suas limitações e não contempla plenamente a realidade do espaço geográfico no qual se insere e ao qual demostra certa diferenciação.

A região não é um recorte sólido, imutável. Dollfus (1978, p. 105) a reconhece "como uma individualidade geográfica, $[. .$.$] um organismo que nasce, se desenvolve e perece". Neste$ sentido a atual definição proposta pelo IBGE (2017) em relação às Regiões Geográficas Imediatas e Intermediárias, próxima daquela apresentada por Kayser (1975), segue em certa 
medida a sequência "orgânica" apresentada por Dollfus (1978), visto que foi o órgão que oficialmente elaborou a primeira delimitação regional oficial para o país, a desenvolveu, aumentando ou reduzindo o recorte; e promoveu a sua extinção à medida que variava os elementos considerados como responsáveis pela diferenciação das áreas.

\section{AS DIVISÕES REGIONAIS PROPOSTAS PELO IBGE}

A subdivisão do território brasileiro em unidades além das federativas foi uma preocupação governamental originada em nível da União ainda na primeira metade do século XX, quando no início do Estado Novo o governo federal determinou pela primeira vez uma regionalização para o país. Intitulada Divisão Territorial dos Estados Unidos do Brasil (IBGE, 1940), a primeira proposta de regionalização para os recortes municipais não fazia referência à conceitos ou critérios geográficos, possuía viés judiciário e administrativo, agrupando os municípios, considerados circunscrições exclusivamente administrativas; e distritos, circunscrições simultaneamente administrativas e judiciárias, em dois recortes exclusivamente judiciários: os termos, compostos por um ou mais municípios em área contínua que tinham como sede a própria cidade ou a mais importante do seu território, a qual também dava nome à circunscrição; e as comarcas, formadas pela união de um ou mais termos, observados os aspectos da sede e da continuidade territorial (IBGE, 1940).

O aumento demográfico, o crescimento urbano e industrial e a expansão da rede rodoviária entre 1940 e 1960 levou o IBGE a iniciar em 1966 estudos para a elaboração de uma nova regionalização, publicando em 1970 a Divisão do Brasil em Microrregiões Homogêneas. A proposta baseou-se na delimitação de espaços homogêneos e polarizados seguindo a orientação metodológica proposta por Michel Rochefort. Os espaços homogêneos foram definidos pelo IBGE (1970) como formas de organização pautadas em torno da produção e expressos por combinações de fatos de natureza física, social e econômica.

Aproximadamente vinte anos após a adoção da nova regionalização, em 1990 o IBGE publicou a Divisão Regional em Mesorregiões e Microrregiões Geográficas. A nova proposta manteve o respeito aos limites das unidades federativas, utilizando-se do conceito de organização do espaço, definido como “[...] diferentes estruturas espaciais resultantes da dinâmica da sociedade sobre um suporte territorial” (IBGE, 1990, p. 7).

Segundo a nova divisão, a Mesorregião configurava-se como uma área individualizada em uma unidade da federação (um estado) com formas de organização do espaço geográfico 
determinadas pelo processo social, condicionadas pelo quadro natural e articuladas espacialmente pelas redes de comunicação e de lugares (IBGE, 1990). As Microrregiões, por sua vez, foram definidas como parte das Mesorregiões que quanto à organização do espaço apresentavam especificidades em relação à estrutura da produção agropecuária, industrial, extrativa mineral ou animal (pesca), resultantes tanto da presença de elementos do quadro natural quanto de relações sociais econômicas particulares (IBGE, 1990). O conjunto de relações em nível local foi outro elemento considerado pelo IBGE ao instituir as Microrregiões. Tais relações foram consideradas a partir da interação entre as áreas de produção e beneficiamento e pela possibilidade de atender às populações locais por meio do comércio varejista e atacadista ou dos setores sociais básicos (IBGE, 1990).

Quanto à nomenclatura das unidades seguiu-se, no caso das Mesorregiões, as denominações regionais tradicionais; de centros urbanos de grande importância regional; das tradicionais Regiões Metropolitanas; ou da posição geográfica da Mesorregião (IBGE, 1990). No que se refere às Microrregiões ressaltou-se o aporte tradicional, considerando a denominação do município mais tradicional ou antigo e de maior expressão na articulação do espaço; a hierarquia urbana a partir de um centro urbano conforme o estudo Regiões de Influência das Cidades (IBGE, 1987) ou o aporte populacional urbano (IBGE, 1990).

A mais recente regionalização elaborada pelo IBGE, a Divisão Regional do Brasil em Regiões Geográficas Imediatas e Regiões Geográficas Intermediárias foi publicada em 2017. A obra, uma proposta de atualização, traz um novo quadro regional pautado na perspectiva da rede urbana e sua infraestrutura de ligação como elemento-chave quanto à manutenção da coesão territorial (IBGE, 2017). Foi a partir da rede urbana que as Regiões Geográficas Imediatas foram estruturadas tomado como referência os centros urbanos próximos para os quais a população local se dirigia para satisfazer suas necessidades imediatas, como a compra de bens de consumo duráveis e não duráveis, a busca por trabalho, serviços de saúde e educação e prestação de serviços públicos como atendimento em postos do Instituto Nacional do Seguro Social (INSS), do Ministério do Trabalho e da Justiça, dentre outros (IBGE, 2017).

Entre as Regiões Geográficas Imediatas e as Unidades da Federação foram instituídas as Regiões Geográficas Intermediárias que englobaram principalmente Metrópoles ou Capitais Regionais, identificadas pelo mais recente estudo Regiões de Influência das Cidades (IBGE, 2008). Além deste trabalho outros desenvolvidos pelo IBGE também foram utilizados, dentre eles, Divisão Urbano-Regional (2013) e Gestão do Território (2014). 
Especificamente quanto à delimitação das Regiões Geográficas Imediatas foram estabelecidos como critérios a quantidade mínima de 5 e máxima de 25 municípios; o mínimo de 50 mil habitantes; e a presença de ao menos uma cidade classificada como centro de zona B no estudo Regiões de Influência das Cidades (IBGE, 2008). Cada recorte conta com um polo articulador de seu território, é ele, geralmente também o de maior hierarquia urbana, que define o nome da região. Dentre outras especificidades, quando há Regiões Imediatas multipolarizadas sua denominação dá-se a partir do nome de todos os centros de mesma hierarquia ordenados pelo tamanho da população. A nova proposta buscou estabelecer ao menos quatro Regiões Imediatas por estado e o respeitou aos limites estaduais (IBGE, 2017).

Ao longo do tempo, conforme observado, houve maior precisão quanto aos critérios estabelecidos pelo IBGE para a delimitação dos recortes regionais. Parte-se de critérios explicitamente judiciários e administrativos, perpasse-se por conceitos e definiçõos de caráter geográfico e chega-se a elementos relacionados principalmente à rede urbana como base para a regionalização. A abrangência de atuação do IBGE aliada à heterogeneidade territorial brasileira permite questionar, tomando como escala de análise o espaço geográfico local, a pertinência de tais critérios e, consequentemente, dos recortes a partir deles estabelecidos.

\section{A MATA SUL DE PERNAMBUCO E SUAS DIVISÕES REGIONAIS}

\section{Aspectos Gerais da Mata Sul Pernambucana}

Localizada na porção meridional da Mesorregião da Mata Pernambucana, a Mata Sul limita-se ao norte com a Região Metropolitana do Recife e a atual Região Geográfica Imediata de Vitória de Santo Antão; a leste é banhada pelo oceano Atlântico; ao sul faz divisa com o estado de Alagoas; e a oeste limita-se com a região do Agreste Pernambucano.

A economia canavieira, estabelecida desde o século XVI e exercida continuamente ao longo de quatro séculos, de modo direto ou indireto determinou praticamente todos os aspectos que caracterizam a geografia humana da região (MELO, 2012), foi através da cana-de-açúcar ou em sua função que constituiu-se "o sistema regional de relações entre o homem e a terra com suas marcas impressivas e características na paisagem (MELO, 2012, p. 84).

O clima, o relevo, o solo, a hidrografia e a vegetação foram elementos que corroboraram para a instalação e sucesso da indústria canavieira (MELO, 2012, FREYRE, 2013), aliados ao fator "posição", caracterizado pela proximidade do mar por onde a produção era escoada 
(MELO, 2012). A proximidade do litoral, contudo, não promoveu o desenvolvimento de cidades na região. A faixa costeira apresenta ocupação mais rarefeita, baseada na exploração do coqueiro, na pesca e na pequena lavoura de subsistência (IBGE, 1970). Os núcleos urbanos, como Palmares, desenvolveram-se às margens dos rios a partir, segundo Andrade (2011), do fortalecimento do processo de colonização e da necessidade de terras e mão de obra para a expansão dos canaviais.

Devido às condições naturais favoráveis a monocultura canavieira prosperou rapidamente na região. O domínio da cana frente a outras culturas foi célere, assim como sua industrialização (ANDRADE, 2011). A lavoura canavieira chegou a responder por $92 \%$ dos cultivos da região, transformando-a na faixa mais ampla e de maior densidade de produção de Pernambuco e de toda faixa úmida oriental nordestina (IBGE, 1990; MELO, 2012). Na região, ao lado dos mais extensos canaviais localizavam-se as maiores usinas de açúcar do Nordeste, constituindo, canaviais e fábricas, uma só economia e paisagem geográfica, intitulada por Melo (2012, p. 88) "paisagem da agroindústria açucareira".

Apesar da tradicional agroindústria canavieira figurar como importante elemento estruturador da organização regional da Mata Sul a mesma foi inicialmente desconsiderada por algumas propostas de regionalização deste espaço. Apenas na segunda metade do século XX tal elemento passou a ser visto como relevante no processo de regionalização, sendo novamente abandonado na proposta atual.

\section{Divisões Regionais da Mata Sul Pernambucana}

Segundo a divisão regional proposta pelo IBGE em 1940, a Mata Sul de Pernambuco, composta por treze municípios, estava subdividida em sete comarcas, algumas formadas pelo município sede como Água Preta, Amaraji e Escada; outras por mais um termo como Gameleira, que formava uma comarca com Ribeirão; e Quipapá com Jurema, atual município da Região Imediata de Garanhuns. As comarcas com maior quantidade de municípios eram a de Barreiros que, além do município sede, era integrada por Rio Formoso e Sirinhaém; e a de Palmares, que aglutinava em sua comarca os termos de Catende e Maraial (Mapa 1).

\section{Mapa 1 - Comarcas, Zona da Mata Sul Pernambucana (IBGE, 1940)}




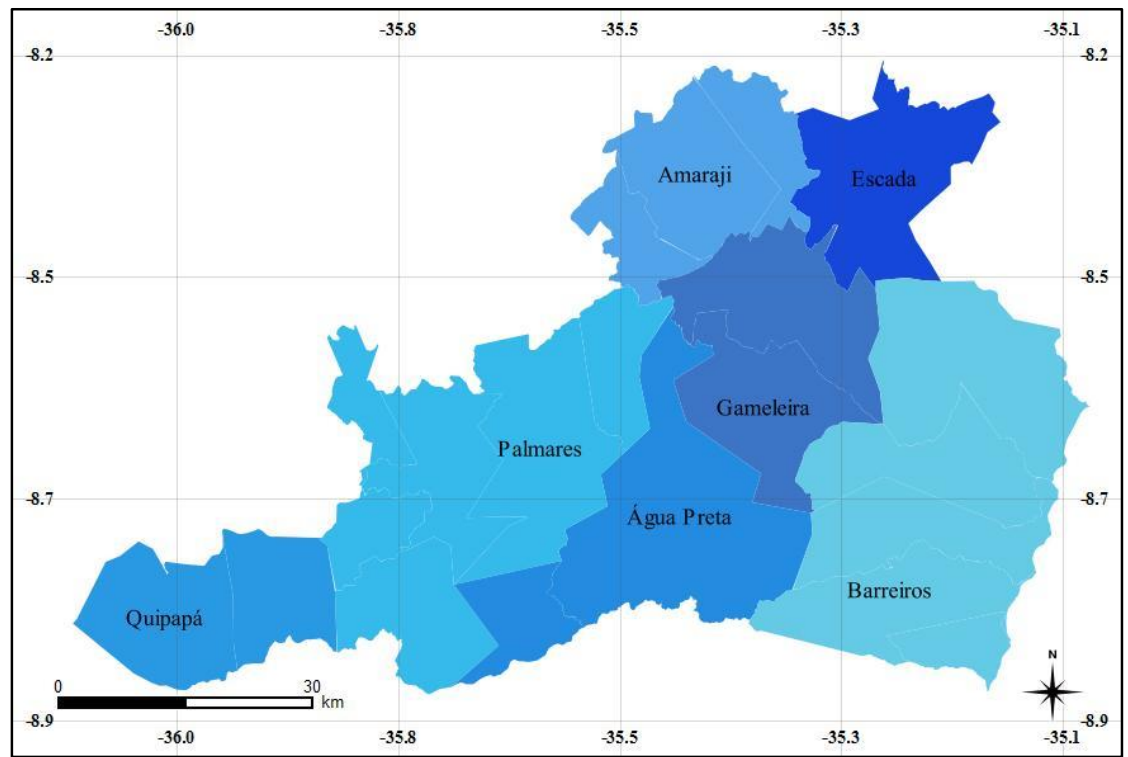

Elaborado por: BARBOSA (2019).

$\mathrm{Na}$ regionalização seguinte (IBGE, 1970), as antigas comarcas e termos foram agrupados sob uma única unidade, a Microrregião Homogênea de número 112 que passou a contar com mais sete municípios, dois a ela anexados: Ipojuca e Vitória de Santo Antão; e cinco frutos de emancipação política: Belém de Maria, Cortês, Joaquim Nabuco, Primavera e São Benedito do Sul. O novo recorte regional passou de treze para vinte municípios (Mapa 2).

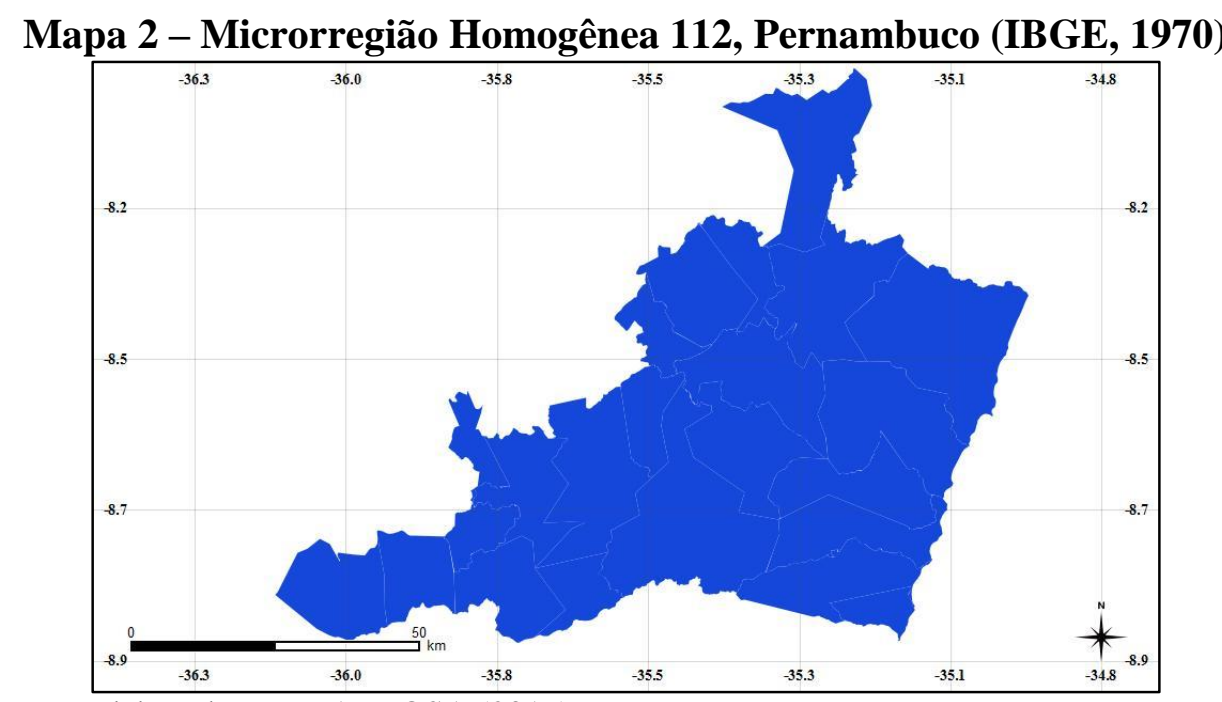

Elaborado por: BARBOSA (2019).

A publicação Divisão Regional do Brasil em Mesorregiões e Microrregiões Geográficas (1990) trouxe poucas alterações para a Mata Sul. A nova unidade regional, intitulada Microrregião da Mata Meridional Pernambucana, passou a ser formada por dezoito unidades com a exclusão dos municípios de Ipojuca e Vitória de Santo Antão (Mapa 3). 


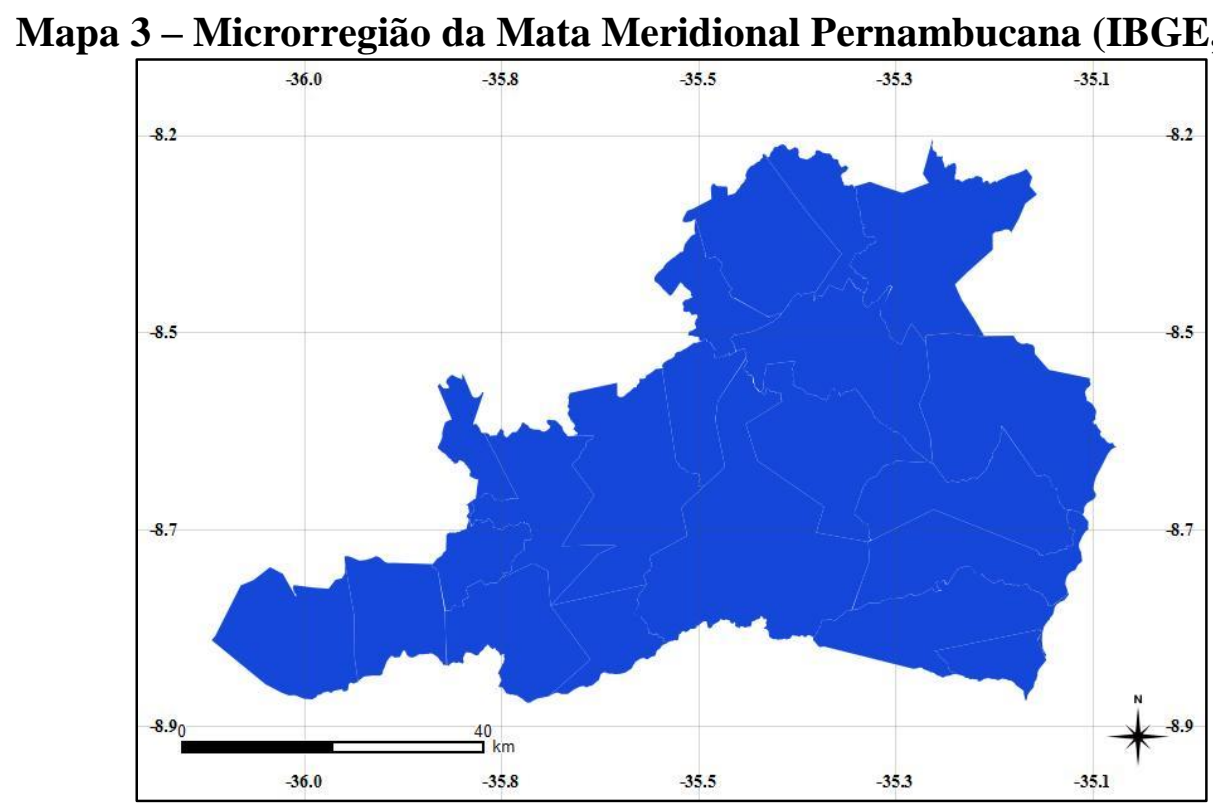

Elaborado por: BARBOSA (2019).

A mais recente proposta de regionalização (IBGE, 2017) subdivide a Microrregião da Mata Meridional Pernambucana (IBGE, 1990) em três novos recortes, as chamadas Regiões Geográficas Imediatas (Mapa 4). Duas das novas regiões são formadas por cinco municípios: a de Barreiros-Sirinhaém que, além das três unidades existentes desde a primeira proposta (IBGE, 1940) conta com o município de Tamandaré, emancipado de Rio Formoso na década de 1990 e São José da Coroa Grande, emancipado de Barreiros nos anos 1950; e a de Escada-Ribeirão que, além dos municípios-sede, engloba Amaraji, Cortês e Primavera. A maior parte dos municípios da Mata Sul compõe a Região Geográfica Imediata de Palmares que engloba dez unidades, dentre elas, Jaqueira e Xexéu, emancipados de Maraial e Água Preta, respectivamente, na década de 1990. O município de Quipapá, presente em todas as regionalizações até então, passa a integrar a Região Geográfica Imediata de Garanhuns.

Mapa 4 - Regiões Geográficas Imediatas, Mata Sul Pernambucana (IBGE, 2017) 


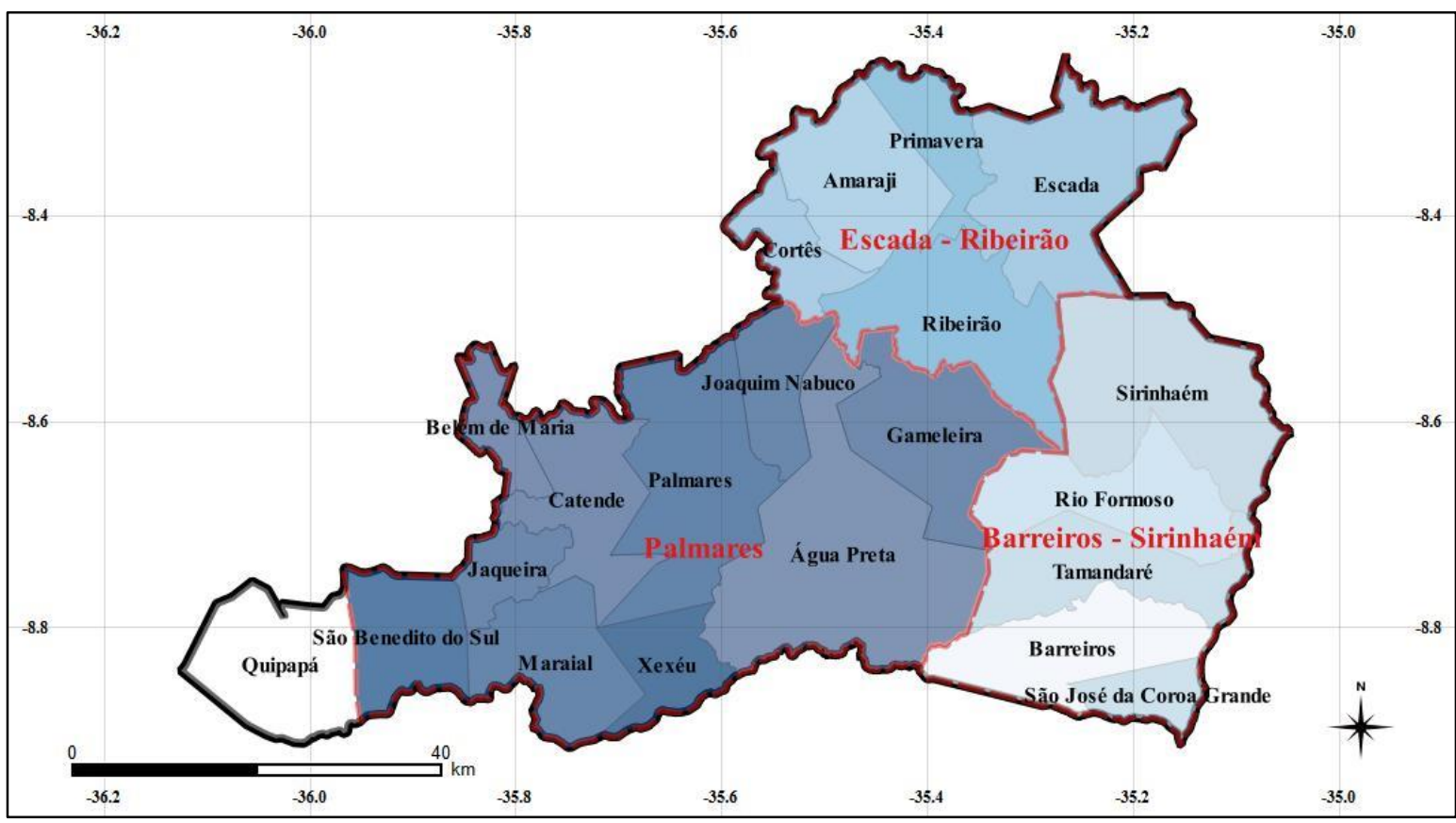

Elaborado por: BARBOSA (2019).

A Mata Sul pernambucana, conforme exposto, conheceu diferentes subdivisões. A região que chegou a ter sete unidades de início tornou-se posteriormente num único recorte que perdurou durante quase meio século até novamente ser repartido na mais recente proposta do IBGE (2017). Os critérios de regionalização do mesmo órgão variaram ao longo do tempo, o mais atual considera a rede urbana, dentre outros elementos, como primordial para a delimitação de novas unidades. Neste sentido, questiona-se a centralidade de algumas cidades quanto à delimitação de Regiões Geográficas por elas encabeçadas.

\section{A REDE URBANA REGIONAL}

Santos (2008, p. 137) ao considerar toda região "por definição um espaço polarizado" ressalta que o mais adequado critério para regionalização seria a análise da zona de influência urbana. Neste sentido, a hierarquia urbana foi considerada pelo IBGE (2017) como um dos elementos-chave no estabelecimento dos novos recortes regionais. Segundo Dolfuss (1978), as regiões são formadas a partir das cidades mediante o estabelecimento de vínculos de complementaridade entre elas e os campos e às relações mais ou menos hierarquizadas entre as cidades que pertencem a uma mesma rede urbana. Analisar a posição ocupada pela cidade e sua relação com os demais núcleos urbanos de sua imediação permitem definir sua centralidade e capacidade de atender à população local articulando efetivamente sua região. 
Nas zonas subdesenvolvidas, segundo Santos (2008), o passado econômico distante ou recente marcado por irregularidades e contrastes promoveu distorções nas relações cidaderegião, sobretudo na atualidade, e, consequentemente, em sua rede urbana, caracterizada, dentre outros elementos, pela falta de centros regionais subordinados e por vezes de centros subregionais. Particularmente quanto à Mata Sul Pernambucana a primeira publicação do estudo Regiões de Influência das Cidades (IBGE, 1987) reconhecia Palmares como único Centro Subregional, maior nível hierárquico da rede urbana na região, enquanto que outras cidades destacavam-se como Centros de Zona alguns de maior atuação, a exemplo de Catende, e outros de polarização mais restrita como Barreiros, Ribeirão e Escada.

Na Mata Sul Pernambucana, uma zona subdesenvolvida, observa-se o predomínio do circuito tradicional da produção e consumo urbanos vinculado às inversões endógenas e integrado às produções regionais desenvolvendo-se mediante o crescimento demográfico e o êxodo rural (SANTOS, 2008). Em áreas deste tipo, segundo Santos (2008), a cidade desempenha quanto à sua região a função de centro consumidor de víveres e etapa entre as áreas que produzem a matéria-prima e as metrópoles ou entre estas e o consumo da população regional, sendo incapazes de exercer um papel de centro regional autônomo. Neste sentido, o mais recente estudo Regiões de Influência das Cidades (IBGE, 2007) continua destacando a posição de Palmares na rede urbana regional como Centro Sub-Regional B, vinculado diretamente ao Recife e polarizador de todos os centros locais da sua Região Imediata (IBGE, 2017), exceto Catende. O único município classificado como Centro de Zona A na região é Barreiros e está diretamente ligado à capital pernambucana. Na Região Imediata de EscadaRibeirão a situação é semelhante. O município de Escada não é listado na publicação, já os demais são classificados como Centros Locais polarizados pela Metrópole Recife (Figura 1).

Figura 1 - Rede urbana, Zona da Mata Sul Pernambucana (IBGE, 2007) 


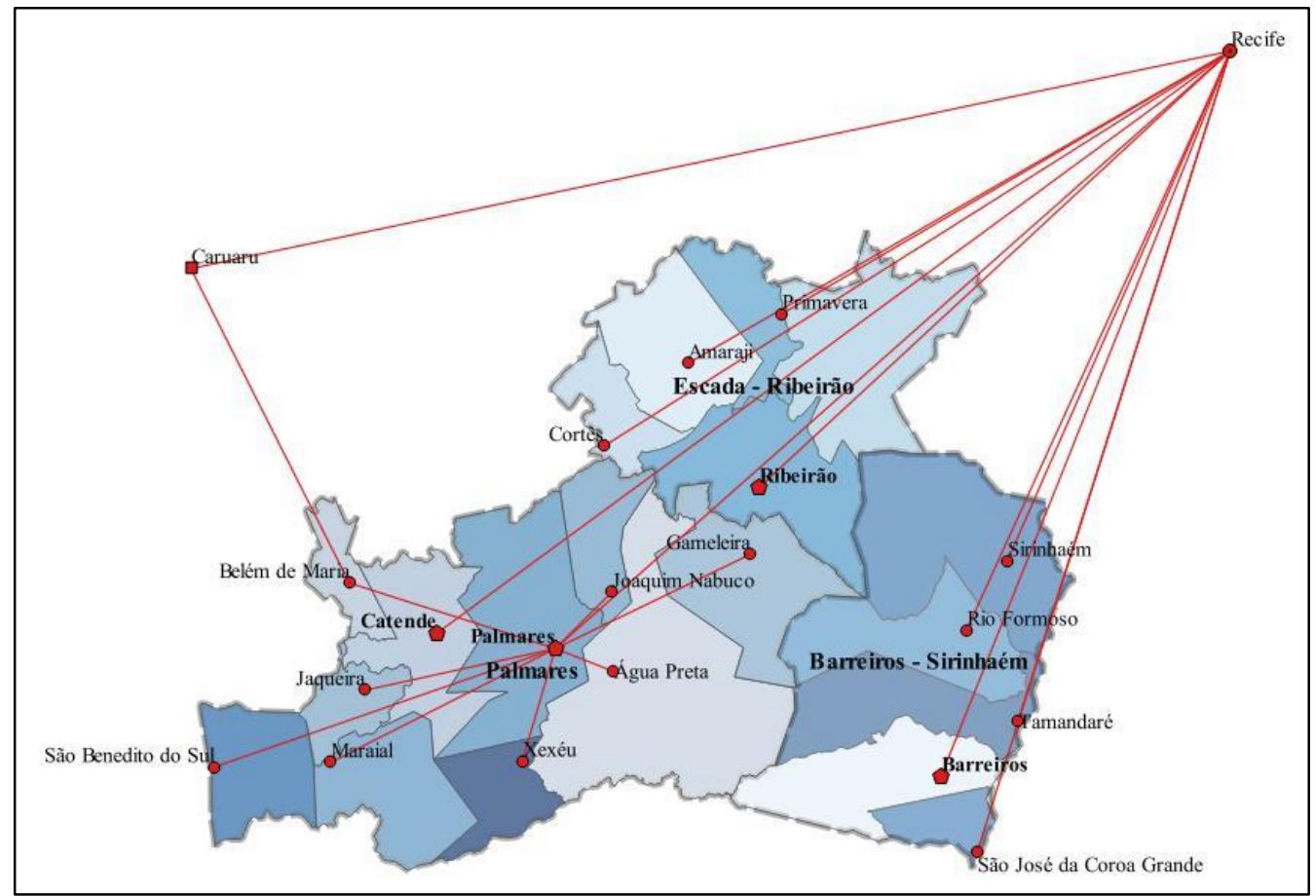

Elaborado por: BARBOSA (2019).

A relevância do Recife como cidade primaz fundada ainda no período colonial, a grande quantidade de pequenos centros com população inferior a 70 mil habitantes (IBGE, 2016) e a ausência de centros intermediários, sendo Palmares a única exceção, permitem identificar a rede urbana na qual estão as cidades que compõem as Regiões Imediatas da Mata Sul Pernambucana como tipicamente dendrítica (CORRÊA, 1994).

Outro documento relevante quanto à proposta de divisão do Brasil em Regiões Geográficas Imediatas e Intermediárias (IBGE, 2017) é o estudo Divisão Urbano-Regional (IBGE, 2013). Segundo a obra as atuais Regiões Geográficas Imediatas de Escada-Ribeirão e Barreiros-Sirinhaém integram a Região Imediata de Articulação Urbana do Recife. Apenas Palmares constitui-se como uma outra Região Imediata de Articulação Urbana.

Partindo-se da definição proposta por Corrêa (1994, p. 8) quanto à rede urbana, que a considera como "um conjunto de centros funcionalmente articulados", os estudos Regiões de Influência das Cidades (IBGE, 1987; 2007) e Divisão Urbano-Regional (IBGE, 2013) permitem concluir quanto às Regiões Geográficas Imediatas de Barreiros-Sirinhaém e EscadaRibeirão que não seria a posição hierárquica dos maiores centros urbanos das respectivas regiões que permitem a sua delimitação, visto que, todos os municípios de ambos recortes (exceto Escada pela ausência de dados) vinculam-se diretamente ao Recife e não às suas 
respectivas cidades-polos. Seria a presença de órgãos governamentais, a oferta de serviços públicos e a atuação empresarial os elementos que permitem delimitar tais recortes?

\section{REGIÕES GEOGRÁFICAS IMEDIATAS DA MATA SUL DE PERNAMBUCO: ÓRGÃOS GOVERNAMENTAIS, SERVIÇOS PÚBLICOS E EMPRESAS ATUANTES}

Além das análises e classificações quanto aos aspectos urbanos, o IBGE considerou questões relacionadas à gestão territorial no processo de delimitação das novas unidades regionais (IBGE, 2017), dentre outros, a partir do estudo Gestão do Território (IBGE, 2014). Neste sentido, partindo-se tanto do supracitado estudo (IBGE, 2014) quanto do raciocínio de Santos (2008, p. 136) no qual ressalta que nos "[...] países subdesenvolvidos as cidades desempenham, em relação às suas regiões, o papel de centros de serviços", serão considerados nesta análise como fatores relevantes quanto à centralidade das cidades em relação às suas Regiões Imediatas a presença de órgãos governamentais relacionados ao INSS; à Justiça Federal, do Trabalho e Eleitoral; ao Ministério do Trabalho e Emprego e à Secretaria da Receita Federal. A concentração de estabelecimentos públicos prestadores de serviços de saúde e de educação básica, e empresas atuantes são elementos complementares analisados.

Quanto à presença de postos de atendimento do INSS, na Região Geográfica Imediata de Barreiros-Sirinhaém o público é direcionado para um dos seus municípios-sede, Barreiros. Em Escada-Ribeirão localizam-se duas agências nos municípios sede: a de Escada, além de atender a demanda do próprio município, atende ao público de Amaraji e Primavera, enquanto que a agência localizada em Ribeirão realiza o atendimento do público local e dos municípios de Cortês e Gameleira, este integrante da Região Geográfica Imediata de Palmares. Os municípios de Água Preta, Belém de Maria, Catende, Jaqueira, Joaquim Nabuco, Maraial e Xexéu, na Região de Palmares, não possuem agência do órgão, tendo suas demandas direcionadas para Palmares. Os segurados de São Benedito do Sul são direcionados para Canhotinho, na Região Imediata de Garanhuns (INSS, 2019).

A atuação da Justiça Federal mediante o Tribunal Regional Federal da $5^{\circ}$ Região ocorre apenas na Região de Palmares que, segundo a Justiça Federal (2019), além de englobar seu recorte, tem atuação sob municípios das Regiões de Barreiros-Sirinhaém (Barreiros, São José da Coroa Grande e Tamandaré) e sob Ribeirão, sede de outra Região. Os municípios das Regiões vizinhas à Palmares que não estão sob sua jurisdição, Rio Formoso e Sirinhaém, na 
Região de Barreiros-Sirinhaém e Amaraji, Cortês e Escada, Região de Escada-Ribeirão, estão sob a jurisdição do Cabo de Santo Agostinho (Região Imediata do Recife).

A atuação da Justiça do Trabalho por meio das Varas trabalhistas se dá, segundo o Tribunal Regional do Trabalho da Sexta Região (2019), em Barreiros que atende toda sua Região Imediata; Escada, exclusivamente à própria demanda; e Ribeirão, que atende Amaraji, Cortês, Primavera e Gameleira (Região de Palmares). Palmares, além de atender sua demanda, é responsável por processos oriundos de Água Preta, Joaquim Nabuco e Xexéu; e Catende, pelo atendimento à Belém de Maria, Jaqueira, Maraial e São Benedito do Sul.

Considerando-se os cartórios eleitorais órgãos governamentais vinculados à Justiça Eleitoral, constata-se, segundo o Tribunal Regional Eleitoral de Pernambuco (2019), sua presença na Região de Barreiros-Sirinhaém em Barreiros, que atende aos eleitores do próprio município e de São José da Coroa Grande; e Rio Formoso, responsável pelo atendimento do público municipal e proveniente de Sirinhaém e Tamandaré. Na Região de Escada-Ribeirão a unidade localizada em Ribeirão atende ao próprio município, Cortês e Gameleira (Região Geográfica Imediata de Palmares); Amaraji possui cartório eleitoral que atende sua demanda e a de Primavera, já em Escada a unidade atende apenas a demanda do próprio município. Na Região de Palmares há unidades no município sede que atendem sua própria demanda; em Água Preta que atende o público de Joaquim Nabuco e Xexéu; e Catende, responsável pelo atendimento dos eleitores de Belém de Maria, Jaqueira e Maraial. O município de São Benedito do Sul tem sua demanda direcionada para Quipapá (Região Imediata de Garanhuns).

Quanto aos órgãos governamentais vinculados ao Ministério do Trabalho e Emprego e à Secretaria da Receita Federal observa-se a presença de agências regionais do trabalho no município sede da Região de Palmares e em Barreiros, uma das sedes de outra Região Imediata (MINISTÉRIO DO TRABALHO, 2019). O município de Palmares conta também com uma agência da Receita Federal (RECEITA FEDERAL, 2019). A Região de Escada-Ribeirão não possui agência dos respectivos órgãos.

Em síntese, quanto à presença dos órgãos de gestão pública considerados, a Região Imediata de Palmares é a mais completa, possuindo representação de todas as instâncias listadas e em alguns casos chegando a prestar atendimento à municípios de Regiões vizinhas. A única agência da Receita Federal da Mata Sul também localiza-se em Palmares, município sede da Região Imediata. As demais Regiões apresentam atendimento a seus municípios apenas quanto 
a algumas instituições (INSS, Vara Trabalhista e Cartório Eleitoral), nos demais casos o público é direcionado para Regiões vizinhas.

A presença de estabelecimentos públicos de saúde e educação básica é outro elemento que permite refletir quanto à centralidade dos municípios em relação às suas Regiões. Neste sentido, constata-se o predomínio das unidades públicas de saúde nas três Regiões Imediatas que perfaziam, em 2009, cerca de $88 \%$ do total de estabelecimentos desta natureza na Mata Sul. Em Barreiros-Sirinhaém havia 48 unidades, sendo Barreiros o município que respondia pela maior concentração. Na Região de Escada-Ribeirão, 54 unidades concentradas principalmente nos municípios-sede e na Região de Palmares localizavam-se 99 unidades públicas de saúde, a maioria também no município sede (IBGE CIDADES, 2019). Os estabelecimentos públicos de educação básica, compunham, em 2017, cerca de 79\% dos estabelecimentos totais da Mata Sul, pouco mais da metade concentrava-se na Região de Palmares, sobretudo em seu município sede, fato observado também quanto aos municípios-sede das demais Regiões Imediatas (IBGE CIDADES, 2019).

A quantidade de empresas atuantes nas Regiões permite observar o grau de atratividade econômica que possuem. Em 2016 a maioria das empresas da Região de Barreiros-Sirinhaém (1378 unidades) localizava-se no município-sede de Barreiros (35\%), seguido por Tamandaré (23\%). Na região de Escada-Ribeirão, as 1327 empresas atuantes localizavam-se principalmente nos municípios-sede, $49 \%$ e $26 \%$, respectivamente. A Região de Palmares era a que concentrava maior número de empresas, com 1722 unidades, em sua maioria concentrada no município sede (cerca de 50\%) (IBGE CIDADES, 2019).

A capacidade de polarização das cidades na rede urbana na qual estão inseridas associada à distribuição de órgãos governamentais e à concentração de estabelecimentos de saúde, educação básica e empresas em alguns municípios e Regiões Imediatas permite-nos a reflexão quanto à sua efetividade e possibilidade de outras regionalizações.

\section{CONSIDERAÇÕES FINAIS}

O termo região por mais que apresente definições próximas é impreciso e necessita ser adjetivado. É a analise regional, importante ferramenta para regionalização, que permite a reflexão quanto à extensão de determinado processo e sua comparação em diferentes escalas espaciais e temporais. Longe de responder qual seria a divisão regional perfeita para os estudos 
acadêmicos ou para o planejamento estatal, o presente texto buscou apresentar as limitações de qualquer regionalização independentemente do agente que a propõe.

As diferentes regionalizações elaboradas pelo IBGE ao longo do tempo nem sempre tiveram seus elementos claramente apresentados, a exemplo da divisão do território em termos e comarcas nos quais prevaleciam as relações entre as unidades mas sem especificamente identificar sua natureza: econômica, política, jurídica, dentre outros.

As novas regionalizações propostas pela instituição valorizaram aspectos e termos da ciência geográfica tornando a delimitação dos novos recortes muito mais compreensível mesmo em alguns momentos não nomeando-os, apenas enumerando-os, e por vezes distanciando-se das próprias regras que estabelecia quanto à nomenclatura das unidades, o que, não permitiria, por exemplo, que a microrregião Mata Meridional Pernambucana fosse assim chamada, pois não considerou elementos pertinentes à denominação das unidades desta tipologia, como o município mais tradicional ou antigo da região e de maior expressão quanto à articulação do espaço, a hierarquia urbana local ou o contingente demográfico urbano. Segundo tais regras uma denominação mais fiel seria Microrregião de Palmares, pois este era o centro que mais chegava próximo das exigências apresentadas.

A valorização da rede urbana como elemento chave na definição de novos recortes, assim como outros critérios de regionalização, que necessariamente demanda escolhas e renúncias, tem suas limitações. A variedade geográfica brasileira nem sempre registra centros urbanos capazes de articular as cidades menores do seu entorno e produzir um recorte singular, a Mata Sul Pernambucana neste sentido é exemplar. Formada historicamente pelo desenvolvimento de atividades ligadas ao campo e não à cidade construiu-se ao longo do tempo apenas um centro urbano regional de maior dinamismo, este, quando não reconhecido por regionalizações anteriores, foi subvalorizado, equiparado a centros menos dinâmicos.

$\mathrm{Na}$ busca por recortes regionais mais próximos à realidade houve a associação de elementos não urbanos como critérios para a formação de agrupamentos. A existência de órgãos vinculados à gestão pública, de oferta de serviços públicos de saúde e educação básica foram importantes elementos identificadores que, quando não serviram para refutar as delimitações apresentadas, contribuíram para demonstrar a concentração espacial em determinadas regiões ou especificamente em certas unidades que as compõem. $\mathrm{O}$ mesmo pode ser observado quanto à atuação de empresas, que reforçam a importância dos centros urbanos a partir da identificação da sua localização e concentração comparativa a outras áreas. 
Na Mata Sul Pernambucana, portanto, duas das três Regiões Geográficas Imediatas propostas pelo IBGE não configuram-se necessariamente como tais, dada a própria limitação que apresentam quanto ao atendimento imediato do seu entorno no que tange a vários critérios. As Regiões de Barreiros-Sirinhaém e Escada-Ribeirão, apesar de compostas cada uma por cinco municípios e possuir mais de cinquenta mil habitantes, critérios mínimos exigidos, são ausentes de centros urbanos de elevada hierarquia, ao menos quanto às características consideradas pelos estudos recentes do IBGE. O município de Barreiros, que ocupa a maior posição hierárquica considerando as duas regiões, não mantém significativa polarização com os municípios do seu entorno, todos estão sob a influência da capital pernambucana, fato que se observa também quanto às unidades que integram a Região de Escada-Ribeirão. Ambos recortes, dentre outras características, não possuem jurisdição própria quanto à Justiça Federal nem agência de atendimento da Receita Federal, além de, na Mata Sul como um todo, serem os recortes que menos ofertam serviços de saúde e educação básica e que apresentam o menor número de empresas atuantes. A região de Palmares, por sua vez, é a única que pode ser classificada como uma Região Geográfica Imediata, pois preenche os requisitos estabelecidos quanto à existência de um centro urbano de maior hierarquia capaz de articular seu entorno além apresentar maior variedade de órgãos governamentais e significativa concentração de unidades de saúde, educação básica e empresas.

Diante das limitações das Regiões Imediatas de Barreiros-Sirinhaém e Escada-Ribeirão quanto aos critérios estabelecidos pelo IBGE para definição dos novos recortes, é possível a sugestão de alternativas diante do novo quadro regional proposto. Neste sentido, dois caminhos, não isentos de consequências, poderiam ser tomados e ambos significam a extinção das duas Regiões Imediatas que pouco se caracterizam como tal. Uma primeira possibilidade seria a criação de apenas uma região na Mata Sul, retornando às propostas apresentadas pelo IBGE na segunda metade do século XX. As Regiões Imediatas de Barreiros-Sirinhaém e EscadaRibeirão seriam integradas à de Palmares. O novo conjunto contaria com vinte municípios, dentro do limite máximo estabelecido (vinte e cinco); continuaria a contar com mais de 50 mil habitantes e estaria efetivamente polarizado por um centro urbano de maior posição hierárquica. A segunda possibilidade seria a junção das Regiões supracitadas à Região Imediata do Recife. O novo recorte contaria com vinte e cinco unidades, certamente mais de 50 mil habitantes e seria polarizado pela metrópole recifense. 
Conforme salientado anteriormente, tais proposições trazem mudanças significativas para o quadro regional e sua rede urbana. Ao considerar a opção de uma única região articulada por Palmares poderia ampliar-se o efeito de concentração exercido por esta cidade, por outro lado, tal opção permitiria uma maior integração do litoral sul do estado com o interior próximo e a criação de novas articulações não direcionadas ao Recife. Inserir as Regiões na Região Imediata do Recife, que por sua própria natureza já inclui municípios da sua região metropolitana, seria significativamente divergente diante da realidade urbana da região e das novas unidades. Assim como Palmares, o Recife teria sua polarização ampliada, cabendo-se questionar também a capacidade deste centro urbano em atender às demandas dos novos entes, por outro lado, tal proposta seria apenas o reconhecimento de algo já retratado pelos estudos urbanos do IBGE: a dependência dos municípios frente à capital pernambucana numa típica rede urbana dendrítica.

Por fim, pode-se concluir que efetivamente a Mata Sul Pernambucana conta apenas com uma Região Geográfica Imediata, a de Palmares, as outras, Barreiros-Sirinhaém e EscadaRibeirão, não se configuram atualmente como tais recortes.

\section{REFERÊNCIAS}

ANDRADE, Manuel Correia de. A terra e o homem no Nordeste: contirbuição ao estudo da questão agrária no Nordeste. 8. ed. São Paulo: Cortez, 2011.

"Espaço e tempo na agroindústria canavieira de Pernambuco". Estudos Avançados. vol.15. no.43. pp. 267-280. São Paulo: Set./Dez, 2001 Disponível em: <http://www.scielo.br/pdf/ea/v15n43/v15n43a20.pdf>. Acesso em: 25 jan. 2019.

BRASIL. Instituto Brasileiro de Geografia e Estatística - IBGE. Cidades. Disponível em: <https://cidades.ibge.gov.br/>. Acesso em: 26 jan. 2019.

Divisão do Brasil em mesorregiões e microrregiões geográficas. Volume 1. Rio de Janeiro: 1990a. Disponível em:

<https://biblioteca.ibge.gov.br/visualizacao/monografias/GEBIS\%20-

\%20RJ/DRB/Divisao\%20regional_v01.pdf>. Acesso em: 26 jan. 2019.

Divisão do Brasil em mesorregiões e microrregiões geográficas. Volume

1. Tomo 2. Rio de Janeiro: 1990b. Disponível em:

<https://biblioteca.ibge.gov.br/visualizacao/livros/liv2269_3.pdf>. Acesso em: 26 jan. 2019.

Divisão do Brasil em microrregiões homogêneas 1968. Rio de Janeiro:

IBGE, 1970. Disponível em:

<https://biblioteca.ibge.gov.br/visualizacao/livros/liv13891.pdf>. Acesso em: 24 jan. 2019. 
Divisão regional do Brasil em regiões geográficas imediatas e regiões geográficas intermediárias. Rio de Janeiro: IBGE, 2017. Disponível em: <https://biblioteca.ibge.gov.br/visualizacao/livros/liv100600.pdf>. Acesso em 26 jan. 2019.

Divisão Territorial dos Estados Unidos do Brasil. Rio de Janeiro: IBGE, 1940. Disponível em: 〈https://biblioteca.ibge.gov.br/visualizacao/livros/liv13618.pdf>. Acesso em: 24 jan. 2019.

Divisão urbano-regional. Rio de Janeiro: IBGE, 2013. Disponível em: <https://ww2.ibge.gov.br/home/geociencias/geografia/default_divisao_urbano_regional.shtm >. Acesso em: 24 jan. 2019.

Estimativas da população residente nos municípios brasileiros com data de referência em $1^{\circ}$ de julho de 2016. Disponível em: <https://www.ibge.gov.br/estatisticasnovoportal/sociais/populacao/9103-estimativas-depopulacao.html?edicao=9112\&t=resultados $>$. Acesso em: 26 jan. 2019.

Gestão do Território. Rio de Janeiro: IBGE, 2014. Disponível em: <ftp://geoftp.ibge.gov.br/organizacao_do_territorio/redes_e_fluxos_geograficos/gestao_do_te rritorio/gestao_do_territorio_2014.pdf $>$. Acesso em: 26 jan. 2019.

População residente total por municípios de Pernambuco - 1980.

Disponível em: 〈http://www.ipeadata.gov.br/Default.aspx >. Acesso em: 26 jan. 2019.

Regiões de influência das cidades. Rio de Janeiro: IBGE, 1987. Disponível em: <https://biblioteca.ibge.gov.br/visualizacao/monografias/GEBIS\%20\%20RJ/regioesdeinfluencia/Regioes\%20de\%20influencia\%20das\%20cidades_1987.pdf>. Acesso em: 26 jan. 2019.

Regiões de influência das cidades. Rio de Janeiro: IBGE, 2008. Disponível em: 〈http://www.mma.gov.br/estruturas/PZEE/_arquivos/regic_28.pdf>. Acesso em: 26 jan. 2019.

INSS - Instituto Nacional de Seguridade Social. Encontre uma agência. Disponível em: 〈https://meu.inss.gov.br/central/index.html\#/localizador-aps >. Acesso em 25 jan. 2019.

Justiça Eleitoral. Tribunal Regional Eleitoral de Pernambuco. Cartórios Eleitorais. Disponível em: 〈http://www.tre-pe.jus.br/o-tre/conheca-o-tre-pe/cartorios-eleitorais >. Acesso em 24 jan. 2019.

. Justiça Federal da $5^{\text {a }}$ região. Tribunal Federal da $5^{\circ}$ Região. Jurisdição. Disponível em: 〈http://www5.trf5.jus.br/jurisdicao/pe>. Acesso em: 24 jan. 2019.

. Ministério da Fazenda. Receita Federal. Unidades de atendimento ao contribuinte em Pernambuco. Disponível em: 〈http://idg.receita.fazenda.gov.br/contato/unidades-deatendimento/pernambuco >. Acesso em: 24 jan. 2019. 
Ministério do Trabalho. Rede de atendimento em Pernambuco. Disponível em:

<http://trabalho.gov.br/rede-de-atendimento/rede-de-atendimento-do-trabalho/rede-pe>.

Acesso em: 24 jan. 2019.

Tribunal Regional do Trabalho da Sexta Região. Varas do Trabalho de

Pernambuco. Disponível em: <http://www.trt6.jus.br/portal/institucional/varas-do-trabalhode-pernambuco >. Acesso em: 24 jan. 2019.

CORRÊA, Roberto Lobato. Região e Organização Espacial. 3. ed. São Paulo: Ática, 1990.

A Rede Urbana. 2 ed. São Paulo: Ática, 1994.

DOLLFUS, Olivier. O Espaço Geográfico. 3 ed. Rio de Janeiro - São Paulo, 1978.

FREYRE, Gilberto. Nordeste. Aspectos da influência da cana sobre a vida e a paisagem do Nordeste do Brasil. São Paulo: Global, 2013

KAYSER, B. A região como objeto de estudo da geografia. In: GEORGE, P.; GUGLIELMO, R; KAYSER, B.; LACOSTE, Y. A Geografia Ativa. 4 ed. São Paulo: Difel, 1975.

LENCIONI, Sandra. Região e Geografia. São Paulo: Edusp, 2009.

MELO, Mário Lacerda de. Paisagens do Nordeste em Pernambuco e Paraíba. 2 ed. rev. Recife: Cepe, 2012. 255 p.

SANTOS, Milton. Manual de Geografia Urbana. 3 ed. São Paulo: Edusp, 2008. 228 p. A Natureza do Espaço. 4 ed. São Paulo: Edusp, 2012. 384 p.

Recebido em Fevereiro de 2019

Aprovado em Junho de 2019

Publicado em Agosto de 2019 